MATEC Web of Conferences 44, 01077 (2016)

DOI: $10.1051 /$ matecconf/20164401077

C) Owned by the authors, published by EDP Sciences, 2016

\title{
Research on Tactics of English Teaching to College Students by Modern Media Technology
}

\author{
Gang Zhou \\ College of Foreign Language Education, Beihua University, Jilin City, China
}

\begin{abstract}
Modern colleges are faced with the dual pressures of university reform and international competition, how to overcome difficulties, to play the role of modern English teaching in colleges and colleges to enhance the core competitiveness of colleges, colleges and colleges modern English teaching problems to be solved. Based on the current situation of modern colleges in the premise of the Modern media platform fully demonstrated the characteristics and viability of the Modern media English teaching, the necessity of modern English teaching of college Modern media. Discusses the Modern media targeting English teaching and important role is in the English teaching to guide the development of modern colleges modern media.
\end{abstract}

\section{General instruction}

Today, with the computer network at the core of modern science and technology has provided us with an unprecedented opportunity and great potential for development; it is the people and people, people and information together. As China's papermaking and printing changed the human civilization spread the same way, the computer revolution has brought people to process and disseminate information in English teaching. IT influence and impact on education has quietly begun, and thus produce a modern form of education. English teaching with modern technology education is also linked to together.1994 proposed a modern definition of educational technology Educational Communications and Technology Association of American technology and modern media technology education, once again caused a big discussion about China's educational technology development and positioning. Our audio-visual sector that "AVE" is China's educational technology; audiovisual education means "the use of modern media, the media, and with the right combination of traditional educational media, educational information transfer in order to achieve optimal education."

But with the development of education and in-depth understanding of educational technology, obviously, AVE's This definition has not properly summarize the connotation and denotation, need not meet the educational development of the representation of educational technology, because: AVE focus on media the lack of a systematic approach, and education is a big system, many of its elements, including audio-visual education, not only in the study of media, including elements of teachers, students, teaching content, just the study of the use of the media, it is impossible to achieve optimal education; galvanic Education refers to the definition of media generated by the media after the fourth revolution in education, does not contain the information revolution appeared fifth multimedia computer and network technology, virtual reality and other digital information technology, some people mistakenly believe that is the traditional slide AVE projection, movies and other media technology applications, is a traditional audiovisual media education; not easy international academic exchanges. Since it is not a substitute AVE modern media technology, then, modern media technology how to define what should be? First let's understand a few concepts related.

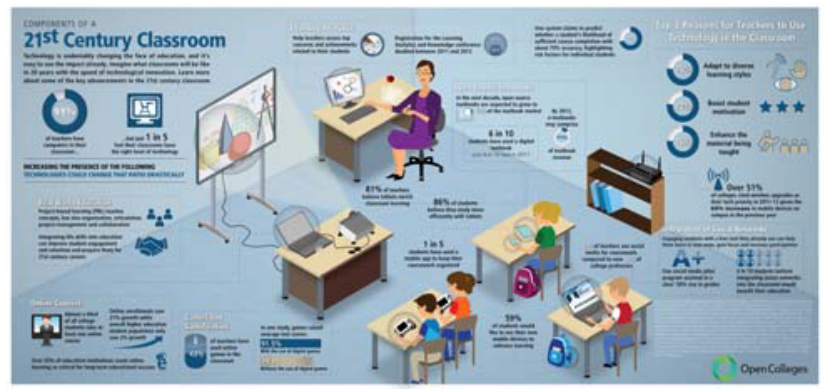

Figure 1. $21^{\text {st }}$ century classroom

\section{Evolution of technology in the field of education and awareness}

Evolution of technology in the field of education and awareness is the definition of educational technology linked with people's practical work, the impact of some of the other disciplines of the field theory (such as cognitive 
psychology, systems theory, etc.) are closely linked to the development of other aspects of the Department a. Since the beginning of this century to the present audio-visual teaching, educational technology has been rapid development, has in 1963, 1970, 1972, 1977 and 1994 five times to give the definition of educational technology. This five defined according to statements can be divided into three categories, the first category (1963, 1994 definition) expresses the main object of study of educational technology, content, research methods and disciplines category; second class (1970 definition) expresses the education technology is both a specific expertise or specific means and methods that educational technology is a media technology, but also a system technology, namely the design, implementation and evaluation of learning and teaching throughout the technology; the third category (1972, 1977 definition) expresses the definition of educational technology in the field, indicating that this area is a some kind of theorybased, learner-cantered, with the resources, the use of a systematic approach to analyze and solve the problem of human learning an integrated complex process.

These definitions from different angles describes the meaning of educational technology, together, we can consider: Educational technology is the sum of all the technical means and methods of human activity employed in education, which is divided into physical and chemical form and intelligent form of two categories, physical and chemical forms of technology refers to the solidification and embodied in a tangible object of scientific knowledge, intelligent forms of technology are those abstract forms, in order to function in the role of scientific knowledge in the form of educational practice. Fred Percival and Henry Ellington in the "Educational Technology Handbook," a book is divided into more specific education technology an integral three parts: First, the hardware, refer to the appropriate technical equipment and teaching systems: software, refers to hardware implementation and design materials: Three pieces of latent means theoretical concepts and research findings related disciplines. 1994 American Association for Educational Communications Technology (AECT) on the modern definition of educational technology as: "Instructional technology is the learning process and learning resources for the theory and practice of design, development, utilization, management and evaluation of" Here, teaching techniques broader sense of educational technology, clearly outlines the study is to learn the process of educational technology and learning resources.

Based on the above analysis, we can see that the three basic attributes of educational technology: (1) Educational technology is the application of a systematic approach to analyze and solve problems in the process of human learning, its purpose is to pursue education optimization: (2) Educational technology division technology for tangible and intangible technology into two categories, tangible technology refers to the use of natural science, engineering and technology achievements, the physical and chemical forms of technology in education, in order to improve teaching efficiency technology that aids ranging from traditional blackboard, chalk, etc. to multimedia computers and networks can be used for education of all equipment, facilities, equipment, etc., and the corresponding software: invisible technology mainly refers to the use of the results of education, psychology, systems science, communication and other aspects of the educational process in order to optimize the technology. (3) Educational technology relies on the development and utilization of all learning resources to achieve their own ends. Learning resources into information, personnel, materials, equipment, techniques and environments, these resources come from two aspects, one is specifically designed for the purpose of learning out of resources, such as teachers, textbooks, instructional television, computer courseware, chalk board, projectors, classroom, playground, lectures, classroom discussions, and the other aspect is the real resources that can be utilized in the world and some of the Central Plains, for example, all walks of life experts, modern sappers, film, exhibitions, museums, production site, games, contests and so on.

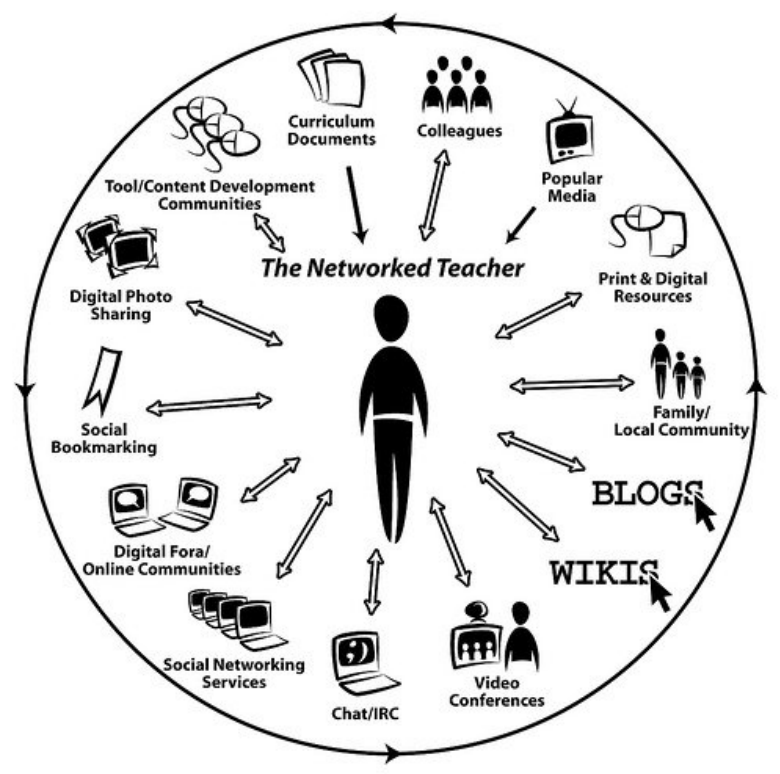

Figure 2. The networked teacher

\section{Technical aspects of educational technology}

Technical aspects of educational technology include education and education technology, education technology is materialized technology, is reflected in educational media technology itself. It is the use of natural science and engineering and technological achievements, membership in order to improve teaching effectiveness and teaching effectiveness. Educational technology refers to a non materialized technology refers to the choice of textbooks and teaching aids, teaching activities designed to plan, control of the teaching process, evaluation, management and other issues, it is from the perspective of education to study the problem of educational technology. Science and technology 
education on the use of psychological theories of learning outcomes, research teaching content, teaching methods, membership in order to improve teaching effectiveness and teaching effectiveness.

Modern media technology and a general sense of educational technology is not essentially different, highlighting the "modern" word is more attention to those with modern science and technology to explore issues related to the absorption of modern scientific and technological achievements and systems thinking approach is more educational technology characteristics of the times. Consolidated results of the international community and with China's actual educational experts of many different teaching and exposition of modern technology defined, I think the modern media technology should be defined as: modern media technology is the modern media theory and the most advanced science and technology applied to the field of education, teaching and learning through the optimization process and the development of teaching and learning resources, teaching model, design, utilization, management and evaluation, in order to achieve the optimization theory and practice of teaching, improve teaching quality and cultivate highquality talent .

The current way of educational technology applications including multimedia combination of classroom teaching, distance learning mode satellite television, interactive multimedia computer to individual learning styles, teaching Internet-based remote communications, virtual reality simulation teaching. In fact, the modern media technology has displayed its strong advantages: (1) information display diversity education; (2) hypertext Education Information Organization: (3) interactive educational process; large (4) Teaching Information storage capacity: (5) teaching transmitted information network; (6) the teaching of intelligent information outlet.

Conform to the development of modern media technology, schools need to focus on the completion of the following basic tasks: (1) the rational allocation of equipment, construction of modern media technology environment; (2) the development of educational software, building a modern textbook system; (3) to carry out teaching experiment, explore the construction modern teaching model; (4) strengthening teacher training, modernization of teachers; the use of educational technology generation, the corresponding need to change the following elements of the relationship between the teaching process: the transformation of the role of a teacher from teacher-centred to explain those changes in student learning the mentors and organizers: change the status of a student's status change from passive acceptance to active participation, found that the dominant position of inquiry and knowledge construction: the role of the media in a shift from a teacher to explain the changes in presentation tools for students cognitive tools: changing the teaching process to explain the process of transition from one note through the creation of scenarios to study the problem, consult learning, meaning construction and other student-centred process.

\section{Modern English teaching in college}

As a large state university college of energy is the basis for the development of the national economy, is to enhance China's comprehensive national strength, reflecting the superiority of the socialist market economy, the window, I was an important foundation for a stable ruling party, but also realize the important position of our Party's mass line. Modern English teaching of college will be directly reflected in the central role of political party organization in colleges and colleges are an important aspect of management and operation mechanism. With the oil industry's market economic internationalization, colleges have from the previous administration into a national monopoly to participate in international competition in the market economy subject. Therefore, improving the modern English teaching of college based work, for speeding up the economic development of the country's construction and reform of decisive significance, is a modern development of university important organizational guarantee. English teaching of the guiding ideology of "economic catch around English teaching, a good job of English teaching to promote economy, which indicates that the promotion of economic development is the central task and the goal of English teaching work, and English teaching but also for the economy spiritual foundation for development, promote market is economy healthy, orderly and rapid development.

Dialectical relationship between English teaching and the economy shows the English teaching an indispensable position and role, only in this dialectical relationship guidance to determine the exact ideas and methods of modern English teaching in order from a strategic height strengthen the party's base, and promote sustained colleges, stability and development. In the full international competition in modern society, we should take the modern situation and problems, "eighteen" spirit study English teaching is facing, so the modern college party organizations to maintain the advanced nature forever, purity, and full combat effectiveness and creative and cohesion, to enhance the core competitiveness of colleges to contribute to a modern era.

\section{Modern media technology to optimize English teaching reform}

From the above analysis we can conclude that the use of modern media technology to optimize English teaching reform and not just the senior leadership based on the overall understanding of the entire education reform, it is the theory and practice and the inevitable result of choice, especially reasonable use of computer multimedia technology to classroom teaching to bring in efficiency "exponentially" leap, has been for countless dedicated to the cause of education in the practice of the majority of teachers are confirmed. But we also clearly recognize that, with all the modern media media not conventional teaching, every class is not suitable for use, not what courses are taught in multimedia technology as well, but 
not each text is suitable for use multimedia to teaching, it's just the regular teaching very important optimization tool, can never replace the traditional teaching of the teachers on the basic programming tools, techniques and methods, such as a stick figure, but can not affect the teachers play a dominant position.

Therefore, the English teachers in the use of modern media technology, especially multimedia technology to optimize both classroom teaching, to grasp the "degree" of the problem, to identify the modern media technology to optimize the best starting point in English teaching reform, we can not "distracting ', but do not "unworthy", to avoid falling into the following errors: the design of classroom teaching into multimedia courseware, courseware to teach these topics, coach's name, to the end of the display unit was sweeping, all the time classroom teaching with multimedia courseware control up with the idea to go courseware holding students to cause the entire teaching activities were streamlined procedures, the teacher becomes a "machine operator", the students have become a passive receptacle of knowledge, thinking in a rigid state, entire classroom can neither reflect the dominant position of the students, nor the guidance of teachers, became the center of media courseware. This is a serious breach of the principle of the use of multimedia assisted teaching.

Teaching activities should be teacher-student interaction, student interaction collision sparks thinking. Multimedia technology is a means to receive pre-aided teaching effectiveness and use, if all the links are displayed teaching multimedia courseware, one class down does not use the blackboard and chalk, blackboard all the contents should be displayed in the screen on, sometimes the content should not be writing on the blackboard is also presented on the screen, it will lose the exemplary teacher writing on the blackboard to some extent, thereby reducing the time students to think for themselves, a simple presentation tools become teachers on the media. Once the computer fails during use, teachers use computers are not very skilled, can lead to a loss of teachers. Language is a very practical lesson, but in order to demonstrate the main premise, students will lose the opportunity to practice the language, the teacher's activity instead of thinking of students, instead of the language of visual communication and realistic simulation exercises.

\section{Conclusions}

Modern media technology to break the boundaries between the real world and the virtual world, changing the way people exchanges fundamentally. In the modern media, interpersonal communication between the conditions, everyone can hide their true situation; you can speak freely with impunity, to express their views. Thus, it is conducive to the education of college students who learn about the true thoughts, so that their English teaching targeted; also conducive to a more in-depth discussion of the relevant issues, English teaching should produce some of its practical effect.
In the English teaching is the degree of trust between teachers and students how to have been an important factor in the impact and effectiveness of education and quality of education. In traditional teacher-student relationship, both teachers and students are always in a state of inequality, which makes student teachers are often reluctant to tell the truth, it prevents enhance the effect of English teaching. And with the help of SMS, blog, forums and other modern media, the exchange between education and the educated have some hidden, and thus bring a sense of equality of the two sides in the personality, rights and status, there is conducive to the formation of a relaxed and harmonious atmosphere, thereby eliminating the gap between teachers and students, thereby enhancing the degree of trust between teachers and students, English teaching to have good teaching.

Acknowledgements: Research college English translation teaching mode under the guidance of constructivism

\section{References}

1. Liu Hongjun. Several colleges and scientific development thinking. Learning and exploration, 11(2009)

2. Cold dives. Adapt to the modern situation and to explore modern ways-on the petroleum and petrochemical English teaching. Theoretical front, 254(2006)

3. Chen Li. Ways to enhance the effectiveness of grassroots English teaching in colleges and colleges. PARTY SCHOOL, 147(2006)

4. Mr. Zhao. Colleges in Modern English teaching of ideological and political work study. Sichuan People's Publishing House, 2009.

5. Jiang Tiezhu. Famous English teaching. Wenhui Press, 541(2008)

6. Sun Chuanming. English teaching Problems and Solutions. Coastal colleges and science and technology, 362(2005)

7. Xiao Xuebin, Julie. The impact of modern media on the English teaching and its response. Ideological Education Research, 234(2009)

8. Wang Huancheng. Modern trends in the modern media environment of English teaching of college students. Contemporary Education Forum (Management), 142(2010)

9. Lai Yong. English teaching in the modern media environment exploration. Net wealth, 102(2010) 